NOTICE: this is the author's version of a work that was accepted for publication in <Automation in Construction>. Changes resulting from the publishing process, such as peer review, editing, corrections, structural formatting, and other quality control mechanisms may not be reflected in this document. Changes may have been made to this work since it was submitted for publication. A definitive version was subsequently published in Automation in Construction, [VOL 58, (October 2015)] DOI 10.1016/j.autcon.2015.07.001

\section{Structural Health Monitoring in Incrementally Launched Steel Bridges: Patch Loading} Phenomena Modeling

Chacón R., Zorrilla R.

Corresponding author: rolando.chacon@upc.edu

Phone number 0034934017349. Fax Number 0034934054135

Construction Engineering Department, School of Civil Engineering

Universitat Politècnica de Catalunya, Barcelona Tech

\title{
Abstract
}

In this paper, a realistic nonlinear 3D simulation of an incrementally launched steel bridge girder is presented. The numerical simulation accounts for three sources of nonlinearity: geometry, material and boundary conditions. For the sake of depicting the capabilities of the presented numerical model in structural verifications, the study is focused on the patch loading field, a structurally complex phenomenon. Patch loading (or concentrated loading) is one the most typically encountered structural verifications on incrementally launched steel I-girders. The presented realistic simulation is based upon an experimentally calibrated numerical model and may provide relevant information at both design and construction stages. For the former, the predictive capabilities of the model for inferring the potential failure due to patch loading are depicted. For the latter, the results obtained are displayed in a way that may be useful for planning a structural health monitoring (SHM) deployment aimed at controlling the patch loading-related phenomena in incrementally launched steel plate girders.

\section{Introduction}

The incremental launching method (ILM) consists of a construction process for bridges in which the superstructure is assembled on one side of the obstacle to be crossed and then pushed longitudinally into its final position. The launching is typically performed statically in a series of increments from one side to another. The (ILM) for bridge construction was first used in Venezuela in a bridge over the Caroni River as described in [1]. Ever since that, the method has evolved technically, economically and in practicality with better launching devices, better control of the pushing systems, better accuracy in topographic field measurements and better understanding of the structural phenomena involved. As a result, it is estimated that thousands of concrete and/or steel bridges have been incrementally launched worldwide [2]. An extensive review of practical applications of the method can be found in [3-7]. The ILM has gained popularity in recent decades among owners and contractors since it may often be the most reasonable way to construct a bridge over an inaccessible or environmentally protected obstacle. The method may guarantee minimal disturbances to the surroundings which may be of a great concern during construction. The ILM, however, may not be the most economical procedure for constructing all bridges. First, at design stages, a thorough structural analysis of a considerable amount of steps is required. The process involves a continuous change of the structural schemes of the bridge with varying geometries, loads and boundary conditions. Second, at construction stages, a considerably specialized construction equipment and expertise are needed. All the potential advantages the ILM may offer when compared to other methods presume that both careful design as well as execution control are provided. The literature describing successful construction procedures using ILM worldwide is vast [8-12]. Third, it is also pinpointed though that works reporting incidents during the ILM process are not infrequent [13-16].

Fig. 1 depicts a 3D view of a hypothetically launched steel girder. Both transversally stiffened and unstiffened cross-sections pass over the supporting bearings. For relatively long girders, the vertical reaction of the bearing induced by the self-weight may be considerably high and potentially harmful for the web when acting over an unstiffened cross-section. As steel girders are typically slender, these reactions may induce an instability-related failure on the web. A concentrate load acting over an unstiffened web of a cross-section is commonly referred to as patch loading. The geometry of the girder (thicknesses $t_{w}$ and $t_{f}$, height $h_{w}$, flange width $b_{f}$, 
distance between transverse stiffeners $a$ and bearing length $s_{s}$ ) as well as the web material properties $f_{y w}$ are determinant parameters on the resistance of steel girders subjected to concentrated loading.

Furthermore, in recent years, Structural Health Monitoring (SHM) has evolved in a considerably fast fashion. Data acquisition and power supply is increasingly more robust [1718]. Likewise, wireless technologies provide feasible means of data gathering during both the life span and/or the whole construction procedures in bridges [19-21]. In last decades, the SHM deployments on incrementally launched bridges have been focused on gathering displacement data as well as reaction forces via load cells or launching devices. Research and field engineering works related to SHM in incrementally launched steel bridges have been reported in recent years in the literature [22-26]

The advent of wireless technologies in SHM opens a considerable amount of possibilities for short- and long-term bridge monitoring [27]. Particularly, in the near future, the whole construction process of incrementally launched steel bridges may considerably be monitored with power-autonomous, wirelessly connected sensors that would eventually provide a vast amount of information to practice engineers. Subsequently, the feasibility of data-gathering diverts the technical difficulties to the need of storing, processing, understanding and visualizing this data deluge. Considerable attention is nowadays paid to data management in SHM in different civil engineering fields, especially for long-term monitoring deployments as shown in [28-31]. SHM deployments should provide sufficient but manageable information to structural engineers. A good balance between both quantity and quality of data requires bespoken deployments for each construction procedure. In each case, a thorough understanding of the most critical structural phenomena involved is compulsory.

In this paper, an experimentally calibrated realistic 3D numerical simulation accounting for geometrical, material and boundary conditions nonlinearity is presented. This numerical modeling provides information that may be used for understanding the patch loading structural phenomenon and thus, for conceiving a meaningful deployment for SHM of incrementally launched steel I-girders aimed at monitoring this potential failure mode during construction. The main objective of the paper is to show to practice engineers, which type of information may be useful when deciding both the type and the amount of necessary monitoring technologies. The numerical simulation is systematically exploited with patch loading, but it may also be extended to other typical verifications such as lateral torsional buckling or shear buckling, which also represent quite frequent structural verifications that have also been considerably studied theoretically, experimentally and numerically.

\section{Review of the earlier work}

\subsection{Patch loading}

A concentrated loading acting over a relatively short length " $\mathrm{s}$ " of an unstiffened cross-section of a plate I-girder is commonly referred to as patch loading. Fig. 2 displays the effect this type of loading may produce on a steel plate girder (only half of a panel is displayed for visualization purposes). If the height-to-thickness ratio $\left(\mathrm{h}_{\mathrm{w}} / \mathrm{t}_{\mathrm{w}}\right)$ of the web is low, the web is prone to fail by local yielding (Fig. 2 left). Conversely, for high $h_{w} / t_{w}$ ratios, the web is more susceptible to buckle prematurely (Fig. 2 right). Between both extremes, a typical plate stability-related hyperbolic transition exists as a function of $h_{w} / t_{w}$.

Patch loading has been the focus of attention of a considerable amount of researchers in the civil engineering field in last decades. Experimental, numerical and theoretical research has been performed since the fifties. The first research works related to concentrated loading were performed for the sake of understanding the elastic critical buckling loads of plates subjected to concentrated loadings on partial edges. A thorough summary of such studies can be found in 
[32]. Subsequently, in the seventies, experimental works performed erected the frame for the development of theoretical mechanical models aimed at predicting the collapse loads of girders subjected to patch loading [33-35]. These models were based upon first order limit analysis. Sequentially, a considerable surge in research devoted to patch loading can be found in Europe during the nineties. Researchers depicted a phenomenological understanding of patch loading and provided accurate expressions for the prediction of ultimate load capacities [36-40]. As a result, accurate design expressions that predict the resistance of steel plate girders subjected to patch loading are nowadays used in relevant design codes.

With the advent of numerical methods, a greater understanding of the phenomenon has been developed and some refinements have been added to the formulation. The particular cases of hybrid girders [41], steel girders with closely spaced stiffeners [42], eccentric patch loading [43], new launching devices [44-45] or studies aimed at studying interactions such as those performed by Graciano and Ayesterán [46] are also available. In all cases, these studies are focused to single isolated panels of a steel girder. As displayed in Fig. 1, these panels are limited by the flanges and the transverse stiffeners separated a distance "a".

\subsection{SHM in incrementally launched bridges}

SHM in ILM depends nowadays on the contractors' capacity and the in situ available technology. For the majority of cases, the control during erection (that may also be understood as short-termed SHM) is performed nowadays via centralized computer controls in order to ensure the simultaneous operation of the entire launching system. The main objective of such deployments is to control accurately the synchronized position, the oil pressure of the launching device, angles and displacements. However, SHM in ILM in remote areas or relatively less developed construction sites is only performed by controlling vertical and horizontal displacement of the launching noses in order to avoid excessive deflection.

Presently, displacements may be tracked in situ by means of Robotic Total Station (RTS) or similar topographic deployments. In addition, the launching devices may nowadays be provided with arrays of sensors which give in real time, information related to lifting and/or pushing pressures. Load reactions of the lifting oil cylinder at pier position may be used as basic reference, and the launching force and displacement of the launching oil cylinder as control parameters. Fig. 3 schematically displays typical hydraulic launching mechanisms for vertical or diagonal lifting.

The oil lifting pressure provides information that can be compared in situ with vertical reaction at the piers obtained from relatively simplistic structural models based upon classical beam theories. Knowing in advance the values of these reactions is useful for preventing any damage related to patch loading. In addition, this particular comparison is crucial when the cross-section of the bridge includes a set of simultaneously launched I-girders. The reactions in all girders are supposed to be adequately proportioned. Any misplacement may alter this proportion and thus, may be detected in real time. This particular type of control may also be useful for preventing a potential lateral torsional buckling failure. Furthermore, a thorough control of the incremental oil pressure may be useful for limiting excessive vibrations during launching.

SHM in ILM includes research and in situ measurements of bridges with a wide variety of shapes [47-49]. Nevertheless, structural control of the ILM involving strains of the web panels has not been widely implemented yet. For the sake of measuring strains in the moving bridge a wireless deployment is practically compulsory. As robustness, power supply and manageable size of sensors is rapidly improving, it is expected that in a few years horizon, strain control of steel girders will be commonplace [27]. In a previous work performed by one of the authors and co-workers [24], the potential use of wireless strain measurement on patch loaded girders was presented. The measurements were performed under a fully controlled environment within laboratory facilities showing the potential of wireless monitoring when launching steel girders. 


\subsection{Realistic computer simulations in incrementally launched bridges}

Recently, computer simulations have contributed profoundly on the understanding of a considerable amount of the phenomena associated with bridge erection. In early 2000's [50] presented the distribution of stresses and strains in patch loaded girders. The simulations described isolated panels with travelling patch loads. More recently, Xu and Shao [51] presented a new type of beam element able to reproduce the varying boundary conditions of reaction typically found in launched girders. In a sequential discussion of a case study (the Hangzhou Jiubao Bridge), Wang et al. [25-26] described a thorough comparison between numerical simulations (with a stepwise nature) and the incremental launching of the bridge. Furthermore, though not dealing with the mechanical behavior of the process, Marzouk et al. [52] presented algorithms aimed at optimizing some of the decisions taken in construction sites during launching. These algorithms deal with material and workforce supply, organization and other important topics. Likewise, Martins and Sampaio [53] presented virtual-reality oriented computer simulations and visualizations of the ILM. These visualizations prove useful in engineering education but also, in planning the construction process. In addition, small- and medium-scale tests aimed at providing a physical understanding of the ILM mechanical nature and the SHM potential have been recently published [54]. These experimental works have been used as benchmarks for the calibration of planar FE-models using beam elements but also, for the calibration of 3D simulations depicted in section 3.

\section{Numerical simulations}

\subsection{General}

A FE-based numerical model is used as a simulation tool. The model is implemented in the commercial Software Abaqus-Simulia [55], in which a vast amount of physical problems may be simulated. The model reproduces realistically the movement of one steel girder over a launching platform towards the intermediate and end supports as shown in Fig. 4. This movement is applied through a large series of considerably small increments. The size of the increment is a function of the total length of the girder (ranging approximately from L/1500 to $\mathrm{L} / 3000$ ). As a result, the incremental procedure is static but nonlinear. The model is capable of reproducing three types of nonlinearity: Geometrical, material and boundary conditions.

The geometry of the simulated bodies is based upon Shell elements. Shell elements allow developing 3D geometries realistically for cases in which one dimension is considerably smaller than the others (in this particular case, the thickness of the plates). The geometrical nonlinearity of a shell-based simulation is based upon two assumptions. The former reads that equilibrium of the system is inferred from the deformed shape of the bodies. The latter implies that there exists a large-displacement compatibility formulation between strains and displacements. Shell-based geometries in thin-walled structures allow developing local and/or global buckling phenomena, which are of the utmost importance in these particular simulations. It is worth bearing in mind that the plates assembling the girders must be provided with an initial imperfection for the sake of appropriately triggering its geometrical nonlinearity. In this work, the initial imperfection (out-of-plane deformed shapes of the web panels) is introduced according to the EN1993-1-5-C recommendations (Eurocode 3. Plated Structures). The magnitude of the maximum out-of-plane imperfection is related to the web thickness $\left(80 \% \cdot \mathrm{t}_{\mathrm{w}}\right)$. Previous works developed by the authors concerning the influence of initial imperfections on the numerical simulations of patch loaded girders (single panels) show further insight concerning this topic [56].

The material nonlinearity for metallic materials is based upon an ideal elastic-plastic constitutive equation. For multi-axial stresses, the uniaxial constitutive equation includes the von Mises criterion. Hardening is accounted for by including an isotropic formulation. 
The boundary conditions are quite particular. The numerical model was expected to reproduce a multi-body physical problem that involved a mechanical interaction between the steel plate and the support conditions. The steel plate girders were modeled with first-order shell elements. The supports were modeled as analytical, rigid and frictionless surfaces on which the steel plates were able to slide and/or transmit contact stresses but conversely, were not able to penetrate through. These analytical surfaces were geometrically defined as objects rigidly connected to the ground. Further information concerning this topic can be found in [55].

The process consisted of a sequential movement (static) of the girder along a given path. In this particular case, the path is defined as a straight horizontal line but may also be defined as circular, for the case of horizontally curved bridges. The process encompasses full nonlinearity for the plate geometry (the webs were provided with an initial imperfection), the material (elastic-plastic with isotropic hardening) and the boundary conditions (a contact-based formulation between bodies). Table 1 and 2 summarize the numerical features of the performed simulations.

\subsection{Validation}

The numerical model was validated throughout a small-scale study performed by the authors and other co-workers in previous works [54, 56-58]. The numerical model of the small-scale test was firstly reproduced with beam elements but subsequently, with shell-based 3D geometries. The small-scale experimental test consisted of a rectangular steel plate launched from one continuous platform to a pair of supports. The final position of the plate generates a two-spanned continuous beam. Fig. 5 displays a comparison between the experimental and numerical results (both beam- and shell-based models). The vertical deflection of the beam throughout the incremental launching process is used for comparison purposes. This magnitude is plotted as a function of the launching progression (Launching progression in Fig. 5). Both beam- and shell-based models show similar results. A good agreement between the experimental and the numerical values is observed.

\subsection{Parametric study}

A parametric study was developed over full scale incrementally launched steel plate girders. The developed simulations consist of a shell-based 3D geometry of a doubly symmetric I-girder of total length 60 meters. The girder is stiffened at a regular spacing "a" that leads to an aspect ratio of the panels $a / h_{w}=2,0$. All plates are assembled with a S355 steel (the material constitutive law is included in Table 1) with standard hardening. The steel girder consists of 24 panels and a 5-meters long launching nose as displayed in Fig. 6 and Fig. 7, respectively. The distance between the launching platform and the intermediate support is 20 meters whereas the distance between the intermediate and end supports is 30 meters. The panels are numbered sequentially from right (panel 1) to left (panel 24). The launching nose consists of a tapered steel girder with similar characteristics of the girders but with tapered web height. In Fig. 6, it is worth pointing out the distance $X_{\text {Launched, }}$ which is systematically used throughout the results discussion. The model consists of a displacement-controlled movement of the end cross-section at panel 24. As a result, $\mathrm{X}_{\text {Launched }}$ in increased from 0 to 50 meters quasi-statically in a series of approximately 1000 steps. It is important to point out that the compressed flanges are not allowed to move laterally. Thus, the potential lateral torsional buckling of these elements is avoided.

A total amount of 20 large scale models were simulated. The set of simulations includes models in which a systematic variation of $t_{w}$ (the web thickness) and $s_{s}$ (the bearing length) was performed. The main objective of this study is to infer the behavior of incrementally launched steel girders with the realistic model. The results obtained are exploited in a twofold fashion: i) for the sake of understanding the patch loading phenomenon in a realistic model, ii) for the sake 
of studying potential SHM deployments in incrementally launched steel plate girders. Table 3 shows the most important geometrical features of such girders as well as the maximum reached distance $X_{\text {Launched }}$ for each model. Other values such as $b_{f}=600 \mathrm{~mm}, h_{w}=1200 \mathrm{~mm}$ and $a=2500$ $\mathrm{mm}$ were held constant. It is worth pointing out that for the first two models, the girders did not reach the total distance $X_{\text {Launched }}=50 \mathrm{~m}$ due to convergence.

\section{Numerical results}

Results concerning displacements, strains, stresses and contact forces at bearing are available for the whole girder at any increment. This amount of data is considerable and must be carefully selected for the sake of meaningfulness. The visualization of the data plays a key role on the phenomenological understanding of the process (patch loading phenomenon) and consequently, on any attempt to set a meaningful SHM deployment. The results are displayed from a broad perspective and subsequently, particular figures, tables and conclusions are extracted from the available set of variations.

Fig. 8 displays the evolution of the vertical deflection for four girders with $t_{w}=6 \mathrm{~mm}$. These particular prototypes have reached the end support $\left(\mathrm{X}_{\text {Launched }}=50\right.$ meters $)$ without showing any instability-related problem (see table 2). The monitored point is located on the edge of panel 1. Expectedly, the vertical displacement follows a cantilever-like shape for $\mathrm{X}_{\text {Launched }}<20$ meters. Once the intermediate support is reached, the deflection is reset since the structural configuration changes. For 20 meters $<\mathrm{X}_{\text {Launched }}<50$ meters, the left end of the girder is fully clampled, with an intermediante simple support and a cantilever for the right end.

It is worth pointing out the deflection varies from one $s_{\mathrm{s}}$ value another. For $\mathrm{s}_{\mathrm{s}}=2500 \mathrm{~mm}$, the contact area is considerably higher than for $\mathrm{s}_{\mathrm{s}}=50 \mathrm{~mm}$. From the plot, one reads that the maximum deflection $\delta_{2500 \mathrm{~mm}}=227,4 \mathrm{~mm}$ and $\delta_{50 \mathrm{~mm}}=295,2 \mathrm{~mm}$, which approximately represents a $30 \%$ increase.

Fig. 9 (a) displays the continuous evolution of the out-of-plane displacement of a node located in panel 10 for girders with varying web thickness $t_{\mathrm{w}}$. This magnitude can be extracted from the 3D model as a novelty when compared to the previously developed beam simulations. In this case, the bearing length $\mathrm{s}_{\mathrm{s}}$ is held constant $\left(\mathrm{s}_{\mathrm{s}}=50 \mathrm{~mm}\right)$. The out-of-plane displacement is considerable greater when the panel approaches the launching platform end as well as the intermediate support. In addition, a trend is observable, as $t_{w}$ increases, the value of the out-ofplane displacement decreases. For the particular case of $t_{w}=4 \mathrm{~mm}$, this value is disproportionally high and warns about the potential failure of this particular panel when reaching the intermediate support. An unrecoverable remaining displacement is noticed afterwards (Fig. 9(b)). A considerable concentrated load is applied on an unstiffened section and the girder fails. Furthermore, the out-of-plane buckling shape undergoes a movement towards the opposite direction (see the difference in signs for those displacements). The realistic model may be used for predicting failure associated with patch loading.

It would also be interesting to know which panel is more susceptible to failing due to patch loading. Depending on the position, the panel bears higher or lower reactions since the structural configuration changes continuously. Fig. 10 displays the maximum recorded out-ofplane displacement (in absolute terms) of all 24 panels of the girders with varying $t_{w}$ and $\mathrm{s}_{\mathrm{s}}=50 \mathrm{~mm}$. For girders with $\mathrm{t}_{\mathrm{w}} \geq 6 \mathrm{~mm}$, the maximum value of the out-of-plane displacement occurs in panel 12 with a rather linear relationship between magnitudes from one panel another. For girders with $t_{w}=4 \mathrm{~mm}$, the out-of-plane displacement is considerably high in several panels (8-12) and the relationship between panels does not follow a similar trend.

On the other hand, Fig. 11 displays the maximum out-of-plane displacement obtained in all simulations from the first series as a function of two magnitudes. On the left side (Fig.11(a)), 
these displacements are plotted as a function of the bearing length $\mathrm{s}_{\mathrm{s}}$ (standardized to the distance between transverse stiffeners). These out-of-plane displacements barely depend on $\mathrm{s}_{\mathrm{s}}$. On the right side (Fig.11(b)), these magnitudes are plotted against the web slenderness $h_{w} / t_{w}$. An expected exponential increasing trend is noticeable. The higher the web slenderness, the higher the obtained displacement is.

Furthermore, stresses, elastic and/or plastic strains, contact forces and other fields are available within the results. These fields provide useful visualization (via renders or videos) of what is physically happening at each increment. Fig. 12 displays the results of three types of fields at 5 different increments (vertical stresses $\sigma_{v}$, plastic strain $p-\varepsilon_{v}$ and contact forces between bodies). These increments are chosen in a way the panel is located over the intermediate support. As a result, a concentrated load travels from one transverse stiffener to another in panel 11. The chosen girder presents geometrical proportions such as $\mathrm{t}_{\mathrm{w}}=4 \mathrm{~mm}$ and $\mathrm{s}_{\mathrm{s}}=50 \mathrm{~mm}$. According to the previously presented results, this particular girder undergoes failure associated with concentrated loading. Several remarks are worth pointing out from Fig. 12.

- At the first chosen increment, the intermediate support is located precisely under the transverse stiffener. Neither local stresses nor plastic strains are observable. The contact forces at this increment are directly transferred to the vertical element.

- Secondly, the load is introduced at an approximate distance of $0,25 \cdot \mathrm{a}$, generating concentrated stresses of considerable magnitude (indicated in dark color). Plastic unrecoverable strain is noticeable at this stage. The plot concerning the contact forces shows a considerable out-of-plane displacement of the whole deformed panel.

- Thirdly, the load is introduced precisely at a distance $0,5 \cdot \mathrm{a}$, generating concentrated stresses of high magnitude. Plastic unrecoverable strain is noticeable and accumulated at this stage. The plot concerning the contact forces shows a considerable out-of-plane displacement of the whole deformed panel.

- Similarly, the distance $0,75 \cdot \mathrm{a}$ and $1,0 \cdot \mathrm{a}$ shows results that follow the same observed trend but in those cases, a remaining plastic strain is observed in the panel.

For the rest of girders $\left(t_{\mathrm{w}} \geq 6 \mathrm{~mm}\right)$, the obtained results show a concentration of forces and stresses as the load travels from one stiffener another but in those cases, no plastic strain is noticeable. Even though the girders undergo a certain level of out-of-plane displacement, these deformations are recoverable. For those cases, the numerical model provides useful information for understanding the patch loading phenomenon as the vertical reaction travels from one stiffener another. As an example, Fig. 13 shows pictorially the evolution of vertical stresses $\left(\sigma_{v}\right)$ on the web at three sequential increments over an intermediate support. In this case, the girder is assembled with a $t_{w}=8 \mathrm{~mm}$ web thickness. These results provide useful information for the mechanical understanding of the coupled shear-bending-patch loading phenomenon occurring at each panel of a full-scale girder.

Fig. 14 displays the vertical strains ( $\varepsilon$ in a row of finite elements of panel 11 when passing over the reaction support for three increments. The row of elements was chosen in the vicinity of the flange-to-web juncture. Similarly, concentrated vertical strains are noticeable as the load moves. For this particular model, the measured strain is far from the yielding point. 


\section{Proposal for SHM deployments}

\subsection{Monitored cross-section.}

The numerical simulation performed on model 9 was used for developing visual plots (from table 3, one may infer $\mathrm{t}_{\mathrm{w}}=8 \mathrm{~mm} \mathrm{~s}_{\mathrm{s}}=50 \mathrm{~mm}$ ). These plots are aimed at tracking particular magnitudes (mainly, strains and displacements) that may be compared to the results obtained in situ during erection. These plots may give to constructors a sense of the physical phenomenon. Consequently, this may help the staff of the site to the structural understanding of the bridge erection. Furthermore, the obtained magnitudes may be compared to real values. It is worth pointing out that these comparisons may be lead to similar results under particular conditions of bridge construction but also, may lead to conflictive results if the conditions of the reproduced model are not similar to the real conditions of the bridge launching (i.e, the bearing length $\mathrm{s}_{\mathrm{s}}$ or the stiffness of the launching shoe may influence certain results). For the case of similar conditions, the continuous monitoring of the process allows to pinpoint any unexpected behavior that may occur.

These plots show the development of longitudinal and/or vertical strains on several points of a selected panel (in this case, panel 11). These points were chosen on top and bottom flanges as well as on the web (at both sides of the plates). Fig. 15 displays an isometric view of the proposed arrangement. The points located at top and bottom flanges provide values related to the longitudinal strain $\varepsilon_{\mathrm{L}}$. In situ, uniaxial wireless strain gauges may provide similar information. The points located on the web provide information concerning the vertical $\varepsilon_{\mathrm{v}}$ as well as principal $\varepsilon_{1}-\varepsilon_{2}$ strains. This information may be extracted in situ by means of a wireless three-axial strain gauge (commonly referred to as rosetta). Fig. 16 displays the precise location of the points from which strains are numerically obtained.

Analyzing the results obtained:

- Firstly, Fig. 17 displays the evolution of the numerically measured longitudinal strains in points located in the outer face of the flanges (numbered 3-12) at panel 11. In a perfectly controlled, symmetric launching, these magnitudes should present identical values (opposite in sign). A similar plot can be obtained in pairs of points (1-10) or alternatively from points located on the inner faces of the flanges (4-11 and/or 2-9). The usefulness of plots of this nature would be to detect any considerable non-symmetric behavior but additionally, to pinpoint potential yielding of the monitored point when compared to the yielding thresholds added to the figure.

- Secondly, Fig. 18 displays a set of plots with information concerning the numerically obtained strains at points located on the web (pairs 5-6 at mid-height and 7-8 at quarter of the height). From these points, longitudinal $\left(\varepsilon_{\mathrm{L}}\right)$, vertical $\left(\varepsilon_{\mathrm{v}}\right)$ as well as shear strains are extracted (the latter referred to as $\varepsilon_{\mathrm{L}-\mathrm{v}}$ ). It is worth pointing out that in situ, it is more likely to deploy tri-axial gauges which would provide strains contained within the plane (generally, $\varepsilon_{\mathrm{v}} \varepsilon_{\mathrm{L}} \varepsilon_{45^{\circ}}$ ). In any case, with three monitored directions at one point, all other strains (invariants, other directions, etc) may be obtained by hand calculations. The evolution of longitudinal strains $\varepsilon_{\mathrm{L}}$ at points $7-8\left(0,25 \cdot \mathrm{h}_{\mathrm{w}}\right)$ shows a considerable increment of such values as the girder reaches the maximum cantilever length (sagging deformation). Once the support reaction is reached, the strain is recovered. Subsequently, the cantilever of the second span generates a higher value for both cases. The trend observed in points $5-6\left(0,5 \cdot \mathrm{h}_{\mathrm{w}}\right)$ is rather different. The strain values are close to zero except when the panel is located over the reaction supports. The concentrated loading generates a localized deformation of the whole panel. The evolution of vertical strains $\varepsilon_{\mathrm{V}}$ shows a similar behavior for both series of measurements $\left(0,25 \cdot \mathrm{h}_{\mathrm{w}}\right.$ and $\left.0,5 \cdot h_{w}\right)$. The strain values are close to zero except when the panel is located over the 
reaction supports. The concentrated loading generates a localized deformation of the whole panel. In some cases, for both sides of the plate, the strains differ in sign, which means considerable bending strains (not only membrane) occur. The evolution of the shear strain is more difficult to link with the structural behavior of the element but is compulsory to track for further transformations or calculations of the strain state of those points.

- Finally, Fig. 19 displays a plot with information with the evolution of the maximum principal strains at $0,5 \cdot h_{\mathrm{w}}$ and $0,25 \cdot \mathrm{h}_{\mathrm{w}}$ locations. These values are obtained from the plots displayed above by hand calculations. The results correspond to the membrane strains (average between both sides of the plate). These values are worth monitoring for inferring potential yielding of the web plate during launching. These strains are higher as the cantilever length increases.

\subsection{Proposal for definition of failure or malfunctioning of the process.}

A SHM deployment in launched steel plate girders may provide useful information for inferring a potential failure or malfunctioning of the process. In section 5.1, figures related to a successful launching are provided (no failure is noticeable in such figures). There are, however, hints observed in other simulations that may provide useful information during launching that may define failure or irregularities during the process.

- Fig. 9 displays the out-of-plane displacement of a node in a loaded panel. For girders with no observable failure due to patch loading, this out-ofplane displacement increases up to a maximum as the panel bears the vertical reaction and subsequently, the panel fully recovers the original shape. For the case of girders in which a patch loading failure is observed, this displacement is unrecoverable. The out-of-place displacement may be used as a potential indicator of failure. For this purpose, a systematic measurement of such magnitude in web panels is desirable. The numerical model presented herein gives hints to designer related to the potential needed instrumentation.

- Fig. 12 displays the evolution of plastic strains in a loaded panel as the reaction is applied at four different stages. The plastic strain is accumulated and unrecovered. This magnitude may also be used as an indicator of failure. The numerical model presented herein provides useful information concerning plastic strain at design levels. One suggestion for defining a potential serviceability threshold, is to establish a percentage of maximum allowable strain at design stages (with a particular emphasis in monitoring such measurements in situ)

- Fig. 17 shows the evolution of longitudinal strain in two gauges located in top and bottom flanges (left side of the girder according to Fig. 17). Their expected behavior is identical with opposite signs. Similar plots can be performed in gauges located in the right side of the girder. Any malfunctioning of the process may be monitored if these strains do not present a symmetrical behavior. A continuous comparison between top and bottom flanges for both left-right values may provide information about the structural behavior. In addition, as displayed in Fig. 17, threshold lines indicating yielding may be added with a corresponding warning system. Nowadays, the symmetric behavior is often monitored via reactions when 
two girders are launched simultaneously. Reactions at both sides are expected to provide approximately symmetrical values. If it does not happen during launching, the operation is stopped and other alignments are verified.

\section{Conclusions}

In this paper, an experimentally validated nonlinear 3D numerical model aimed at reproducing the mechanical behavior of a steel plate girder during bridge launching is presented. Doubly symmetric steel I-girders are incrementally launched from one horizontal platform to the corresponding supports in a continuous quasi-static sequence of numerical increments. During this process, a continuous monitoring of displacements (vertical and horizontal), strains and stresses as well as contact forces is obtained as a result. These magnitudes can be extracted from the model at any increment (or position of the girders) and at any point of the whole model. The numerical model involves three sources of nonlinearity: geometrical, material and the boundary conditions.

The presented numerical simulations are systematically employed in a manifold fashion:

- For detecting a potential failure due to concentrated loading during launching. The continuous nature of bridge launching implies that rather high reactions occur at unstiffened cross-sections when the girders are located in particular positions. The model is able to predict such potential harm and might be useful for structural designers.

- For understanding the travelling patch loading phenomenon in a steel girder at failure. The continuous nature of the process implies that as the reaction moves between transverse stiffeners, plastic unrecoverable strains may be accumulated throughout the launching.

- For predicting numerically the results concerning strains and displacements. The model might be useful at construction stages when comparing the numerical results with values obtained in situ. In addition, the model allows the designer to pinpoint the most unfavorable panels (those which are supposed to bear higher reactions) from which meaningful information concerning longitudinal and/or vertical strains may be extracted. The model is useful when designing SHM deployments. At this point, the numerical model may feed the SHM project which may also feedback the results for further calibrations.

Further refinements of the numerical simulations are being developed by the research group. Lateral torsional buckling, which may also condition the design and construction of launched bridges may be included by developing simulations with unrestrained (or partially restrained) compressed flanges. In subsequent simulations, temperature-related displacements as well as the corresponding coupling with the mechanical ones may generate more realistic simulations. Finally, it is worth pinpointing that further studies concerning the phenomenological insight of this type of loading may be extracted from these simulations. Consequently, the model might be useful for research as well as for teaching-visualization purposes. It is worth pointing out that the presented numerical simulation should be enhanced with real data obtained from incrementally launched bridges. Consequently, new phenomena and/or conditions may be detected. In any case, it is concluded that nowadays, available wireless technologies are prepared for providing this considerable amount of data. In few years, this type of datagathering may become commonplace. 


\section{References}

[1] Leonhardt F., Baur W. Trah W. Brücke über den Rio Caroni, Venezuela, in "Betonund Stahlbetonbau", February. N. 2 v. 61. pp. 25-38 1966

[2] LaViolette M., Wipf T., Lee Y, Bigelow J., Phares B. Bridge construction practices using incremental launching, American Association of State Highway and Transportation Officials, AASHTO, 2007.

[3] Rosignoli M. Bridge Launching, Thomas Telford, 2002.

[4] Gohler B. Pearson P., Incrementally Launched Bridges. Design and Construction, Ernst and Sohn, Berlin, Germany, 2000.

[5] Baur W., Bridge Erection by Launching is Fast, Safe and Efficient, Civil Engineering. ASCE, Vol. 47 (3). pp. 60-63. 1977.

[6] Alistair P., Large and Small Incrementally Launched Structures, Transportation Research Record 1696 (5B0060), pp. 122-130 Transportation Research Board, Washington D.C., 2000.

[7] Zellner, W. and Svensson, H. . Incremental Launching of Structures. Journal of Structural Engineering. Vol. 109 (2). pp. 520-537. 1983

[8] Favre R., Badoux M., Burdet O., Laurencet P., Incremental Launching for the Ile Falcon Bridge, Concrete International, Vol. 21 (2). pp. 46-51 February 1999.

[9] Hewson N., Hodgkinson A., Incremental Launch of Brides Glen Bridge, Ireland, Concrete, Vol. 38 (7). pp. 29-31. 2004.

[10] Zhuravov L., Chemerinsky O., Seliverstov V., Launching Steel Bridges in Russia, Journal of International Association for Bridge and Structural Engineering (IABSE), Vol. 6 (3). pp. 183-186. 1996

[11] Rosignoli M., Monolithic Launch of the Reggiolo Overpass, Concrete International, Vol. 29 (2). pp. 26-30. 2001.

[12] Nader M., Manzanares R, López-Jara J., De La Mora C., Launching of the San Cristobal Bridge. Transportation Research Record. Issue 2040. pp 57-68. 2007.

[13] Beguin G., Catastrophic sliding of a concrete deck during its launching on the steel girders of a composite bridge, Journal of Performance of Constructed Facilities. Vol. 24 (2). pp. 138-1472010.

[14] Marchetti M., Specific design problems related to bridges built using the incremental launching method. Engineering Structures. Vol 6 (3). pp. 185-210. 1984.

[15] Rosignoli M. Misplacement of launching bearings in PC launched bridges. Journal of bridge engineering. Vol. 3 (4). pp. 170-176 1998 
[16] Tanner P., Bellod JL, Sanz D., Hingorani R. Lessons from incidents attributable to the uncertainties in bridge launching illustrated by a case study. Civil Engineering and Environmental Systems. Vol. 30 (2), pp. 146-161. 2013

[17] Casciati S., Faravelli L., Chen Z., Energy harvesting and power management of wireless sensors for structural control applications in civil engineering. Smart Structures and Systems. Vol. 10 (3). pp. 299-312. 2012.

[18] González A., Aquino R., Mata W., Ochoa A., Saldaña P., Edwards A. Open-WiSe: A Solar Powered Wireless Sensor Network Platform. Sensors. Vol. 12 (6). pp. 82048217. 2012.

[19] Hu X., Wang B., Ji H., A Wireless Sensor Network-Based Structural Health Monitoring System for Highway Bridges. Computer-Aided Civil and Infrastructure Engineering. Vol. 28 (3). pp. 193-209 2013.

[20] Gangone M.V., Whelan M.J., Janoyan K.D., Wireless monitoring of a multispan bridge superstructure for diagnostic load testing and system identificacion. ComputerAided Civil and Infrastructure Engineering, Vol. 26 (7). pp. 560-579. 2011.

[21] Chae M., Yoo H., Kim J., Cho M. Development of a wireless sensor network system for suspension bridge health monitoring. Automation in Construction. Vol. 21 (1). pp. 237-252. 2012

[22] Lebet J. Measurements taken during the launch of the $130 \mathrm{~m}$ Span Vaux Viaduct, Steelbridge, OTUA. Millau, France. pp. 133-134. 2004

[23] Wipf T., Phares B., Abendroth R., Chang B., Abraham S., Monitoring of the Launched Girder Bridge over the Iowa River on US 20, Final Report CTRE Project 01108, Center for Transportation Research and Education, Iowa State University. March 2004.

[24] Chacón R., Guzmán F., Mirambell E., Real E., Oñate E. Wireless Sensor Networks for strain monitoring during steel bridges launching, International Journal of Structural Health Monitoring, Vol. 8 (3). pp. 195-205. 2009.

[25] Wang J, Lin J, Chen C, Zhang Z, Simulation Analysis and Control Research of Long Multi-Span Composite Bridge with Incremental Launching Construction. Towards Sustainable Transportation Systems - Proceedings of the 11th International Conference of Chinese Transportation Professionals, pp. 3078-3090. 2011

[26] Wang J, Lin J, Fu Y., Jiang Y., Li J., Zhang Z. Safety Control Research of Steel U Girder of Composite Bridge with Incremental Launching Construction. Applied mechanics and materials. Vol (90-93). pp. 926-932. 2011

[27] Hoult N., Fidler P., Hill P., Middleton C., Wireless structural health monitoring of bridges: present and future. Smart Structures and Systems. Vol. 6(3). pp. 277-290. 2010. 
[28] Ni Y., Xia Y., Liao W., Ko J., Technology innovation in developing the structural health monitoring system for Guangzhou New TV Tower. Structural Control and Health Monitoring. Vol 16 (1). pp. 73-98. 2009

[29] Chen Z., Casciati S., A low-noise, real-time, wireless data acquisition system for structural monitoring applications. Structural Control and Health Monitoring. In press. Vol 21 (7). pp. 1118-1136. 2014.

[30] Meyer J., Bischoff R., Feltrin G., Motavalli M. Wireless sensor networks for longterm structural health monitoring. Smart Structures and Systems. Vol 6(3). pp. 263-275. 2010

[31] Glisic B., Yarnold M., Moon F., Aktan E., Advanced Visualization and Accessibility to Heterogeneous Monitoring Data. Computer-Aided Civil and Infrastructure Engineering. pp. 382-398. Vol. 29 (5). 2014.

[32] Johansson B., Lagerqvist O. Resistance of plate edges to concentrated forces. Journal of Constructional Steel Research. Vol. 32(1). pp. 69-105. 1995.

[33] Roberts T., Rockey K. A mechanism solution for predicting the collapse loads of slender plate girders when subjected to in-plane patch loading. Proceedings of the Institution of Civil Engineers, Part 2, Vol. 67. pp. 155-175 1979

[34] Rockey K., Bagchi D. Buckling of plate girder webs under partial edge loadings. International Journal of Mechanics Science; Vol. 12. pp. 61-76. 1970

[35] Elgaaly M. Web design under Compressive Edge loads. Engineering Journal. Vol. 20 (4). pp. 153-171. 1983.

[36] Markovic N. Hajdin N. A contribution to the analysis of the behaviour of plate girders subjected to patch loading. Journal of Constructional Steel Research. Vol. 21 (1-3). pp. 163-173. 1992.

[37] Kutmanova I., Skaloud M. Ultimate Limit State of Slender Steel Webs Subject to (i) Constant and (ii) Repeated Partial Edge Loading. Journal of Construction Steel Research. Vol 21(1-3). pp. 147-162. 1992.

[38] Lagerqvist O., Johansson B. Resistance of I-girders to concentrated loads. Journal of Constructional Steel Research, Vol. 39 (2). pp. 87-119. 1996.

[39] Graciano C., Lagerqvist O. Critical buckling of longitudinally stiffened webs subjected to compressive edge loads. Journal of Constructional Steel Research. Vol 59 (9). pp. 1119-1146. 2003.

[40] Graciano C., Johansson B., Resistance of longitudinally stiffened I-girders subjected to concentrated loads. Journal of Constructional Steel Research. Vol 59 (5). pp. 561-586. 2013. 
[41] Chacón R., Mirambell E., Real E. Hybrid steel plate girders subjected to patch loading. Part 2. Design proposal. Journal of Constructional Steel Research. Vol. 66 (5). pp. 709-715. 2010.

[42] Chacón R., Mirambell E., Real E. Transversally stiffened plate girders subjected to patch loading. Part 1. Preliminary study. Journal of Constructional Steel Research. Vol. 80 (1). pp. 483-491. 2013.

[43] Gil-Martín L.M., Šćepanović B., Hernández-Montes E., Aschheim M.A., Lučić D, Eccentrically patch-loaded steel I-girders: The influence of patch load length on the ultimate strength. Journal of Constructional Steel Research. Vol. 66(5). pp. 716-722. 2010.

[44] Alonso-Martínez M., del Coz Diaz J.J., Navarro-Manso A., Castro-Fresno D. New mechanism for continuous and bidirectional displacement of heavy structures: Design and analysis. Automation in Construction. Vol 44 (8). pp. 47-55. 2014.

[45] Navarro-Manso A., del Coz Díaz J.J., Alonso-Martínez M., Blanco-Fernández E., Castro-Fresno D., New launching method for steel bridges based on a self-supporting decksystem: FEM and DOE analyses. Automation in Construction. Vol 44 (8). pp. 183196. 2014

[46] Graciano, C., Ayestarán, A. Steel plate girder webs under combined patch loading, bending and shear. Journal of Constructional Steel Research Vol. 80 (1). pp. 202-212. 2013.

[47] Navarro, M., Lebet, J.-P., Beiloune, R., Launching of the Vaux Viaduct, Structural Engineering Int., Vol. 10,pp. 16-18. 2000

[48] Dauner, H-G., Decorges, G., Stucki, D. Web buckling strength for the launching of a box girder with a 130 m main span, Stahlbau, 69, pp. 775-180. 2000

[49] Zhang Y, Luo R. Patch loading and improved measures of incremental launching of steel box girder. Journal of Constructional Steel Research, vol. 68 (1), pp 11-19. 2012

[50] Granath P., Thorsson A., Edlund B., I-shaped steel girders subjected to bending moment and travelling patch loading. Journal of Constructional Steel Research, Vol. 54(3). pp. 409-421. 2000.

[51] $\mathrm{Xu}, \mathrm{R}$. and Shao B., A new beam element for incremental launching of bridges, Journal of Bridge Engineering. Vol. 17 (5). pp. 822-826. 2012

[52] Marzouk M., El-Dein H., El-Said M., Application of computer simulation to construction of incrementally launching bridges, Journal of Civil Engineering and Management, Vol. 13 (1). pp. 27-36 2007.

[53] Martins O.P., Sampaio A.Z., The application of virtual reality technology in the construction of bridge: The cantilever and incremental launching methods. Automation in Construction. Vol. 37 (1). pp. 58-67. 2011. 
1 [54] Chacón R., Uribe N., Oller S., Numerical and experimental study of the incremental launching method of a steel bridge. Experimental Techniques. In press. Available online 9 Dec 2013.

[55] Abaqus FEA, Simulia@ V6.10.3. Dassault Systèmes. 2013.

[56] Chacón R., Mirambell E., Real E. Influence of designer-assumed initial conditions on the numerical modeling of steel plate girders subjected to patch loading. ThinWalled Structures. Vol. 47 (4). pp. 391-402. 2009.

[57] Zorrilla R. Simulación numérica a escala real de proceso de lanzamiento de puente metálico por empujes sucesivos. Bachelor Thesis (in Spanish). School of Civil Engineering. Universitat Politècnica de Catalunya. 2014. http://upcommons.upc.edu/pfc/handle/2099.1/24672

[58] Zorrilla R. Reproducción experimental de puente por empujes sucesivos empleando FEM (Validation of FEM shell model of incremental launching process using experimental data). Eduacero. Vol $2 \quad$ (5). 2013. http://eduacero.com/revista/pdf/2013-2-5.pdf 


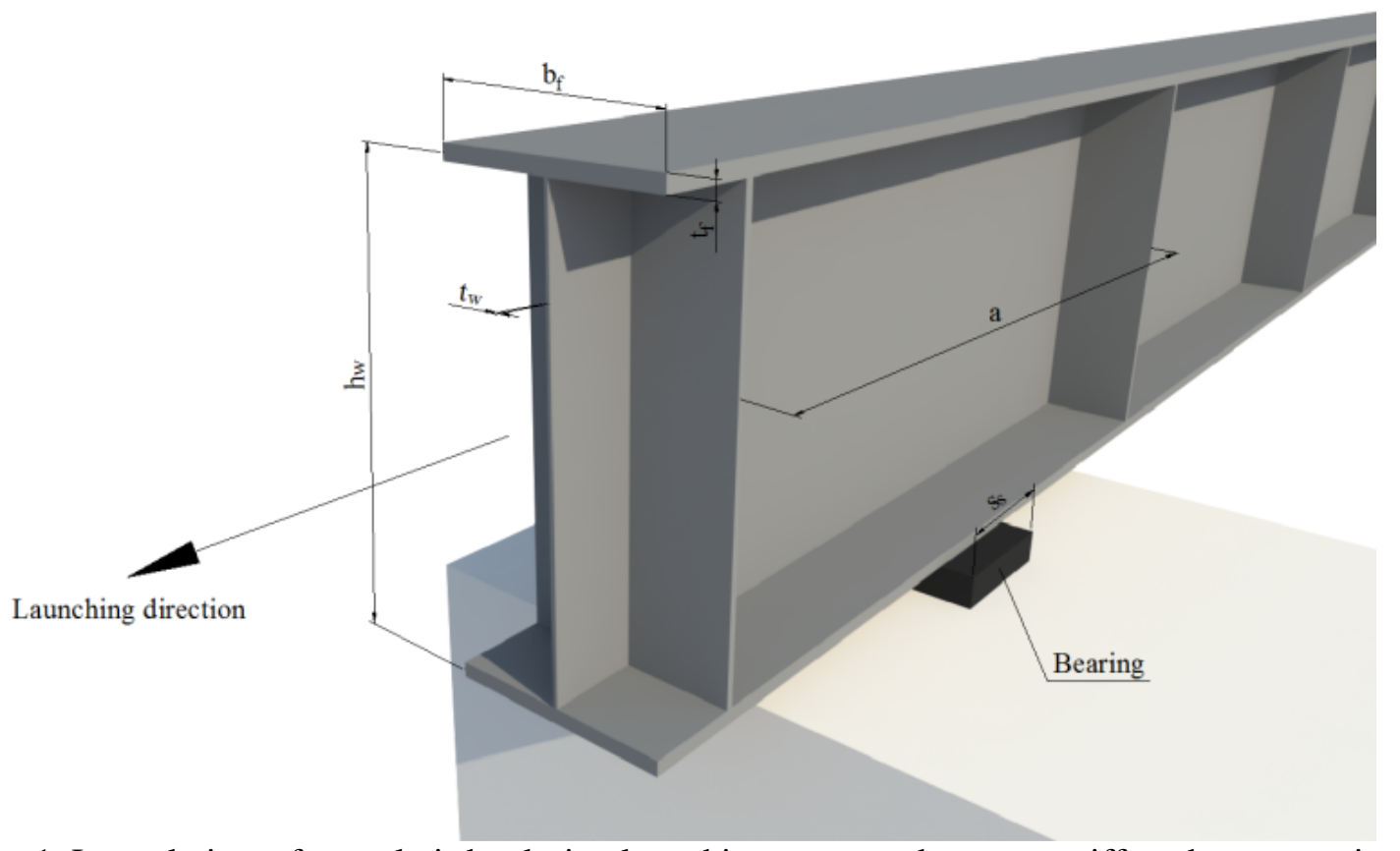
3 4

5 7

8

9

Fig. 1. Lateral view of a steel girder during launching supported on an unstiffened cross-section.
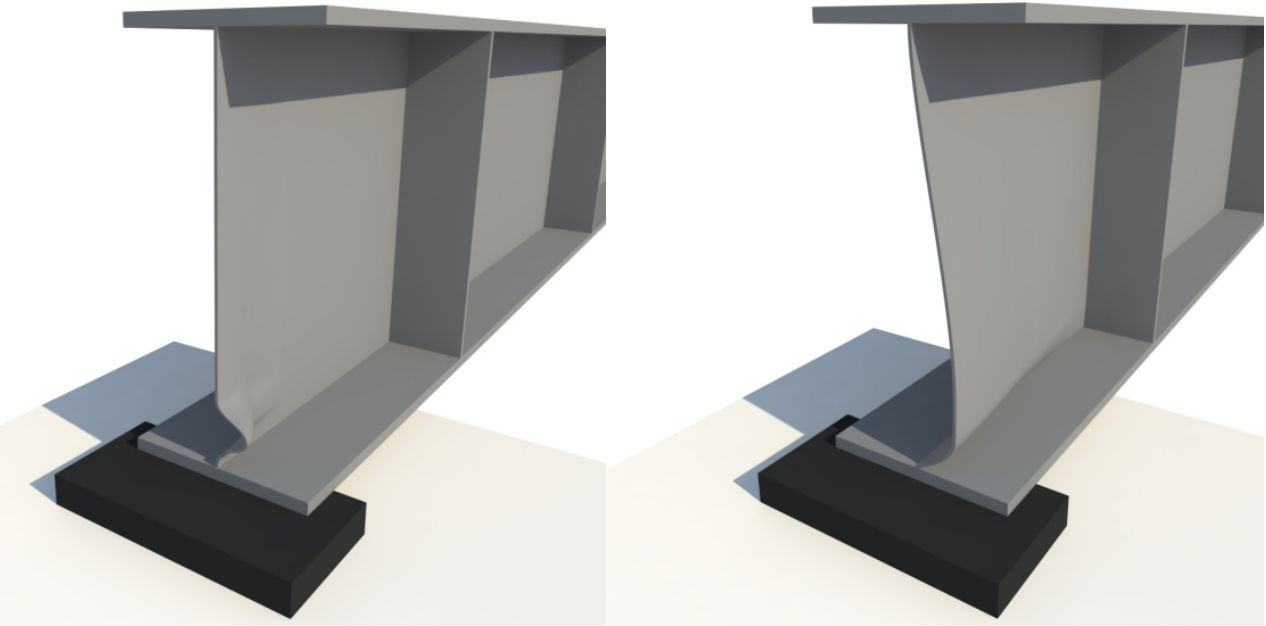

Fig.2 Typical failure mechanisms (shown for half-girder in an unstiffened cross-section) Left: local yielding. Right: web buckling
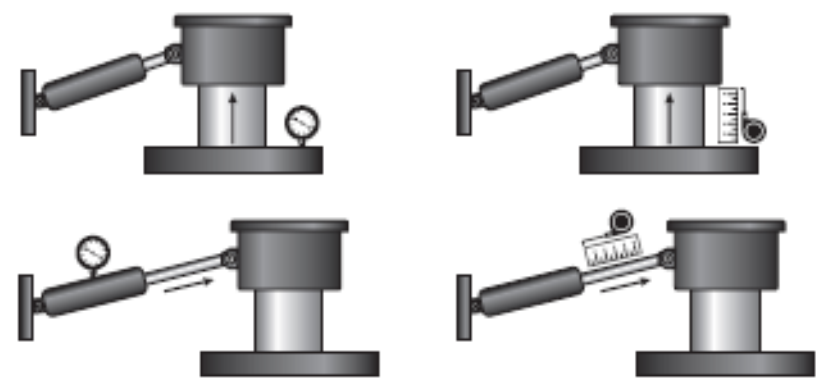

Fig. 3. Schematic view of hydraulic launching-lifting devices with varying mechanisms. 
1

2

3

4

5

6

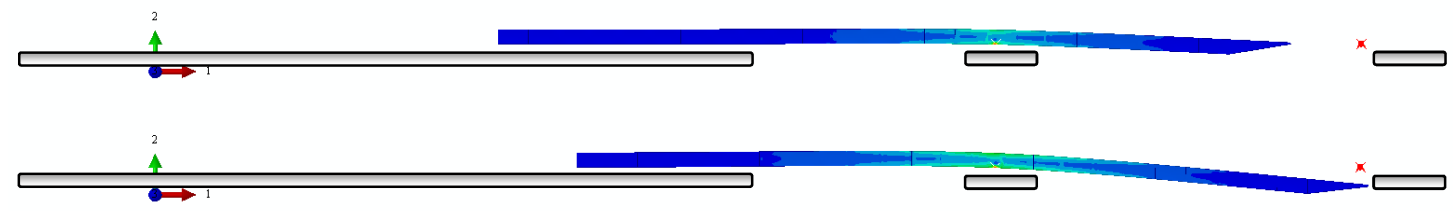

8

9

11

12

13

14

15

16

17

18

19

20

21

22

23

24

25

26

27

28

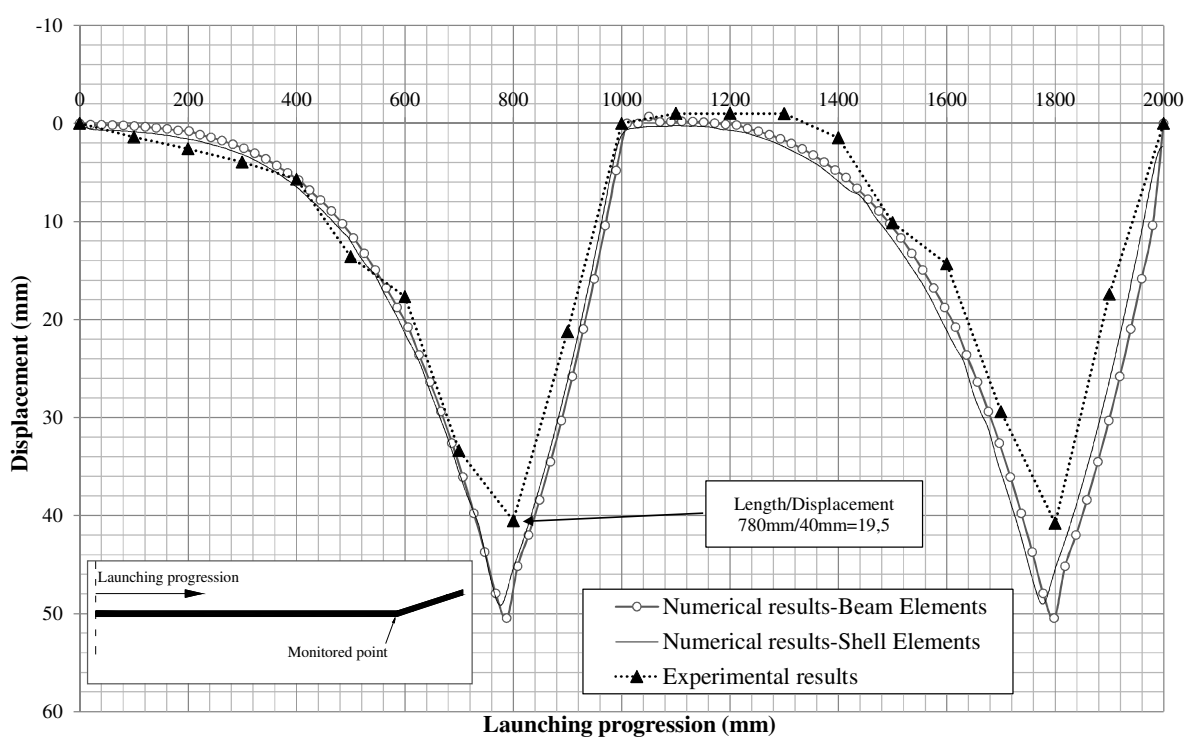

Fig. 5 Experimental vs. Numerical results (beam and shell elements) 
2
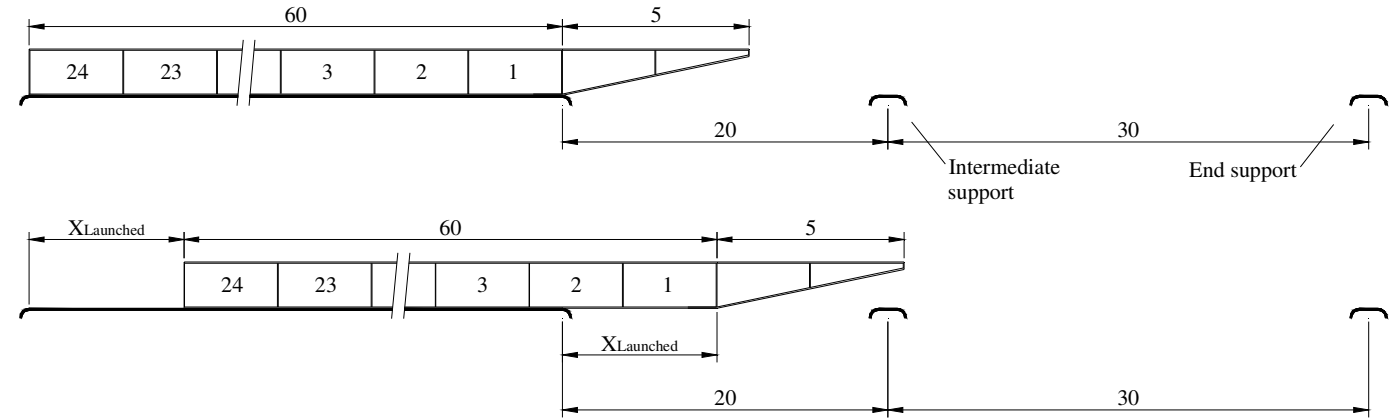

3

Figure 6. Geometrical deployment of the numerical simulations (distances in meters)

5

6

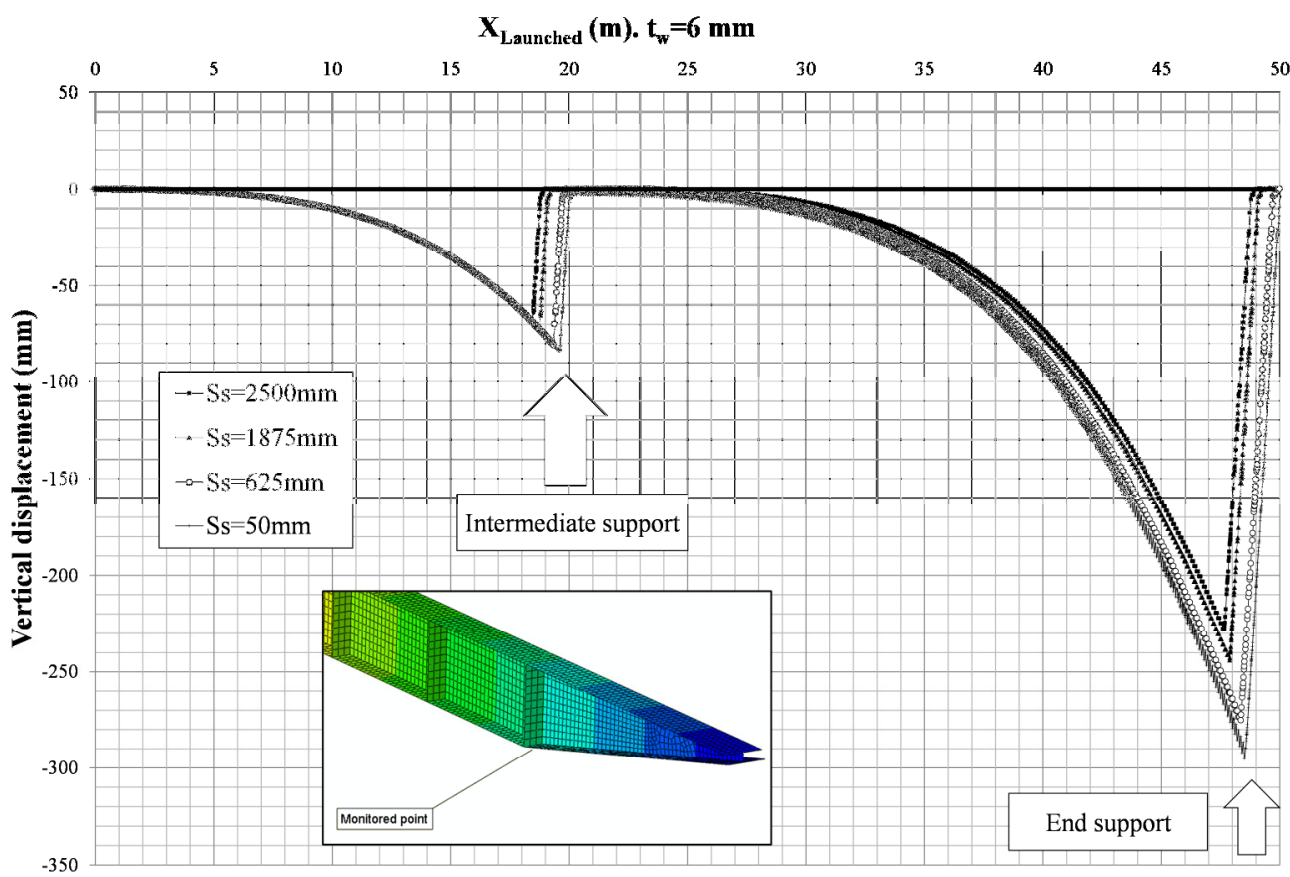

Figure 7. Vertical deflection of the girder during launching. 


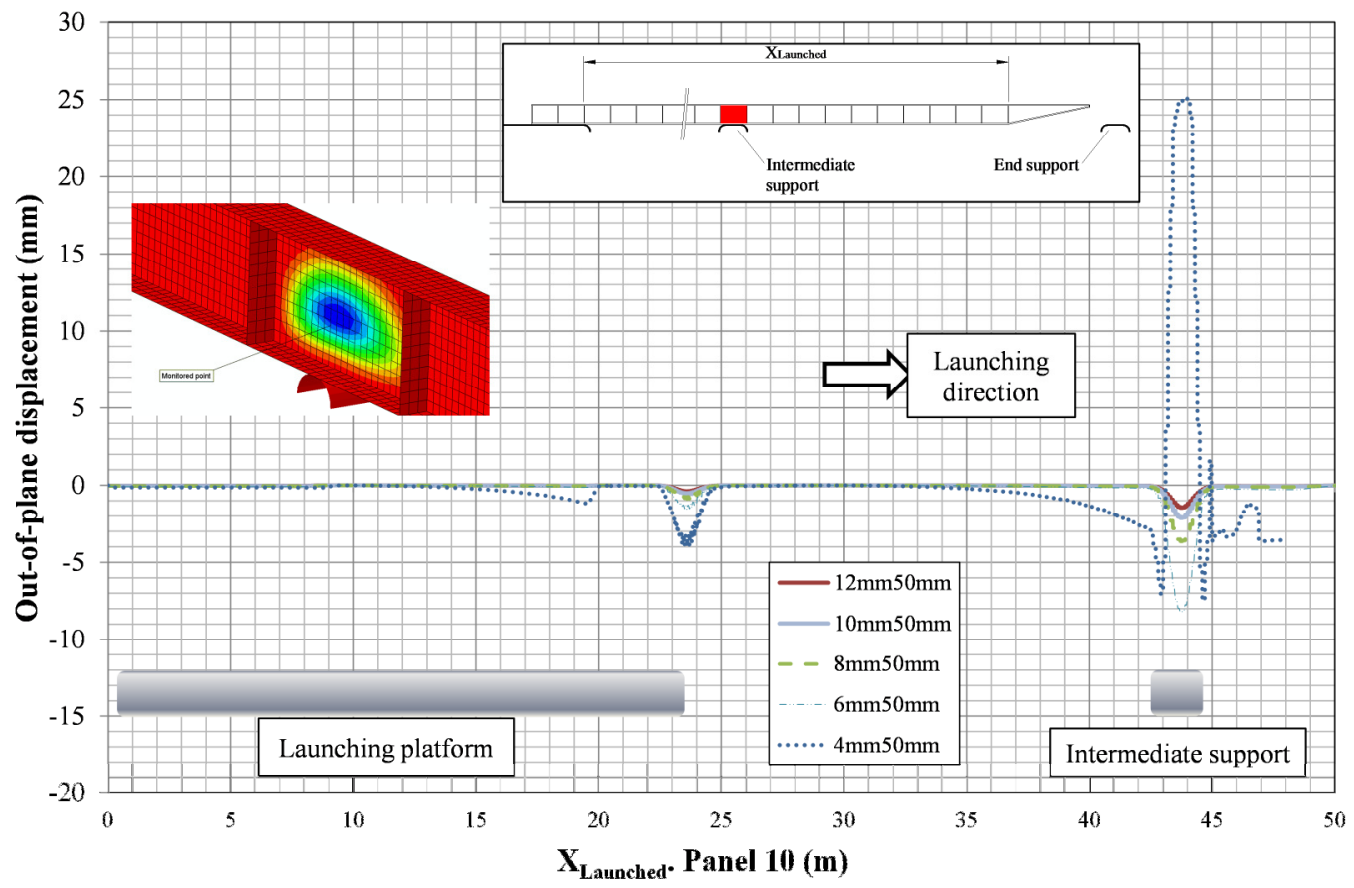

Figure 8. Out-of-plane displacement of panel 10 during launching.

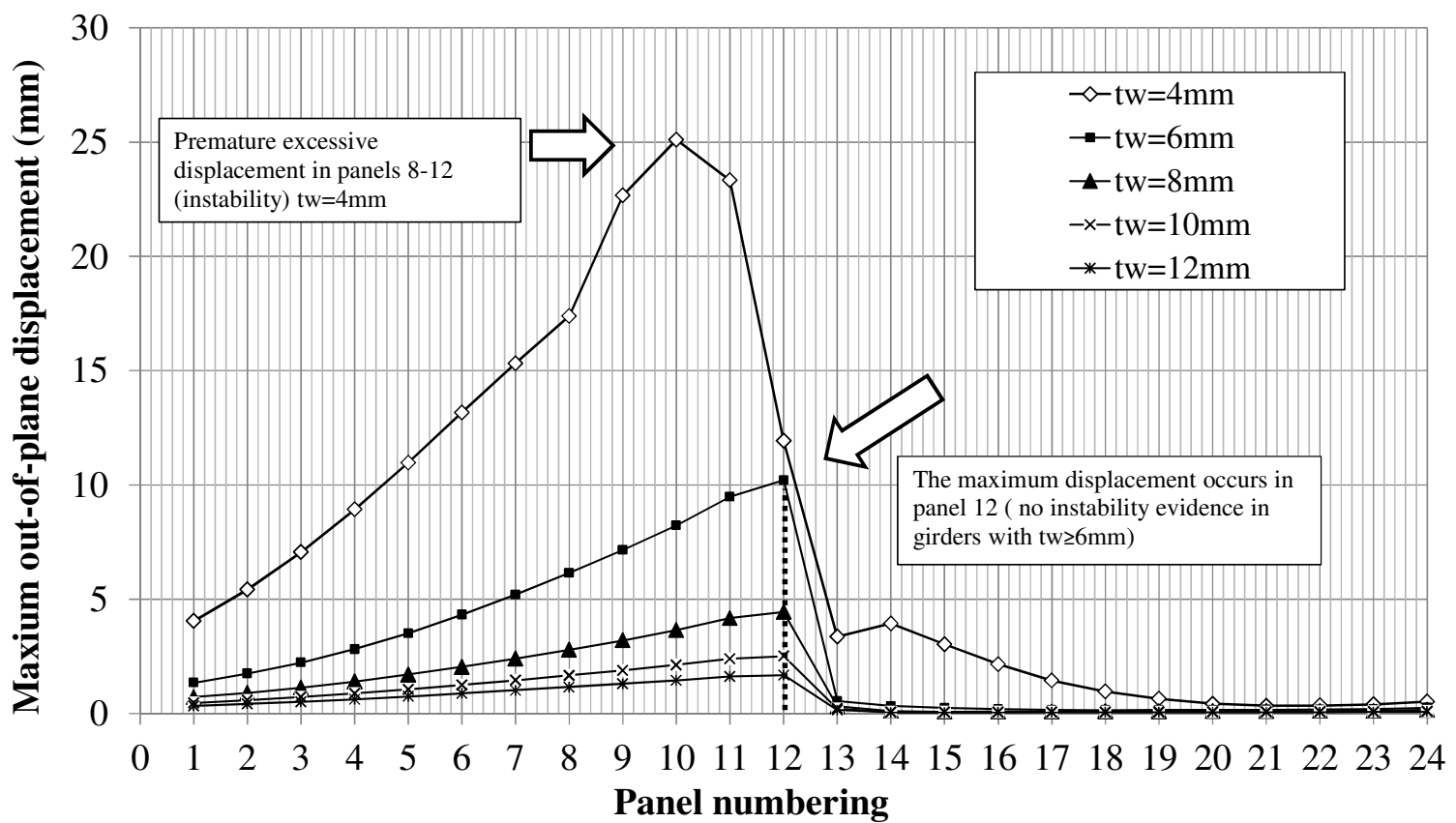

Figure 9. Maximum out-of-plane displacements of all panels of the girders during launching. 

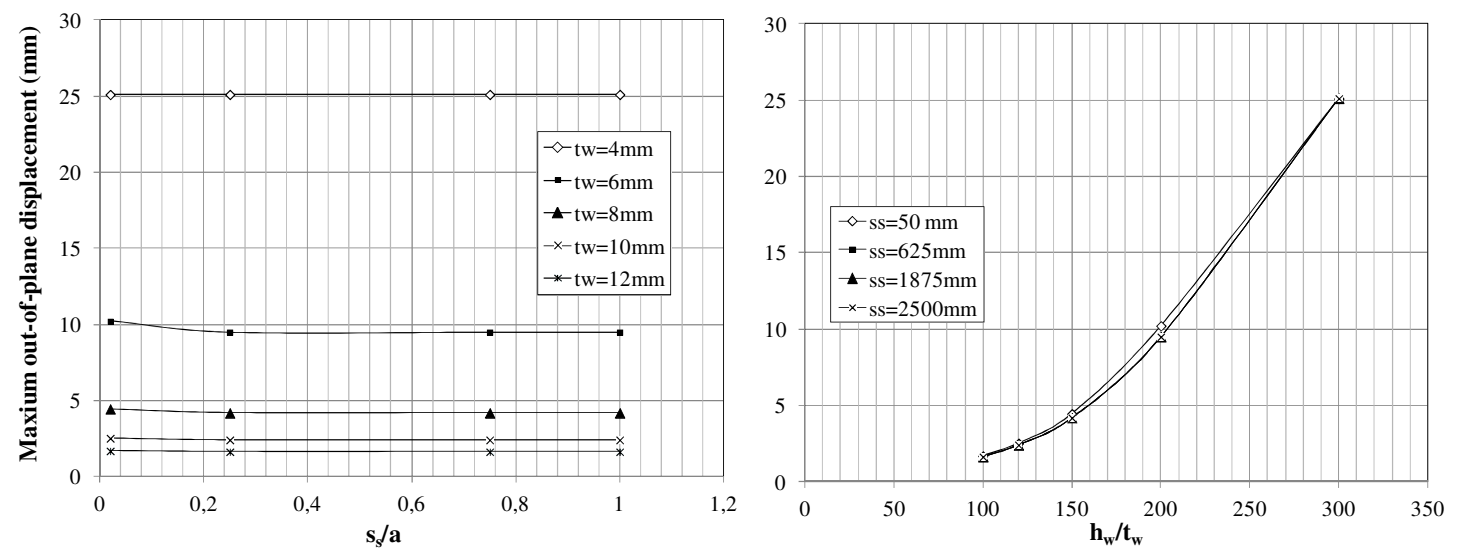
4

5

Figure 10. a) Influence of the bearing length b) Influence of the web slenderness on the response

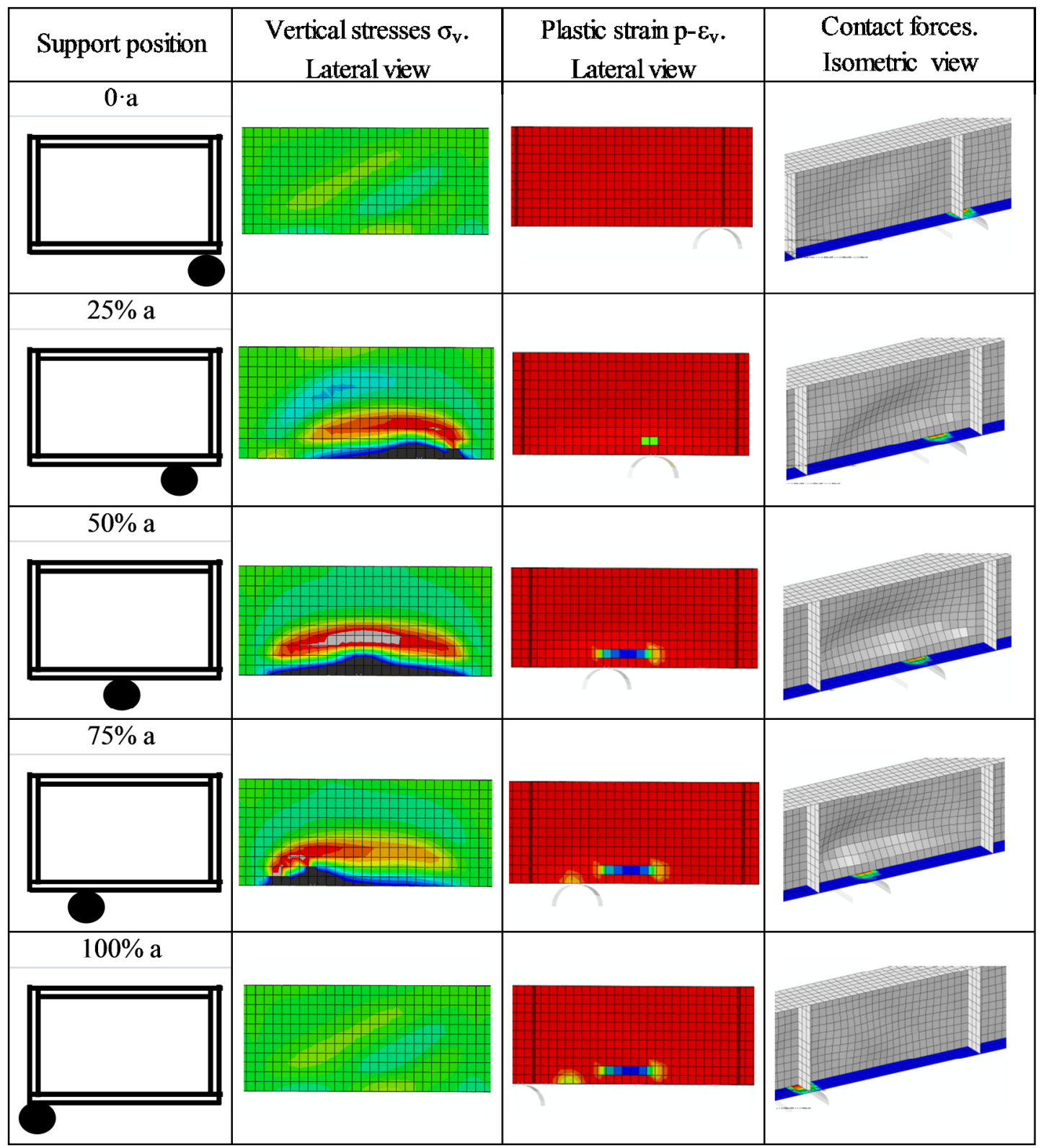

Figure 11. Three types of results available at 5 increments for panel 12 during launching. 
1

2

3

4

5

7

8

9

10

11
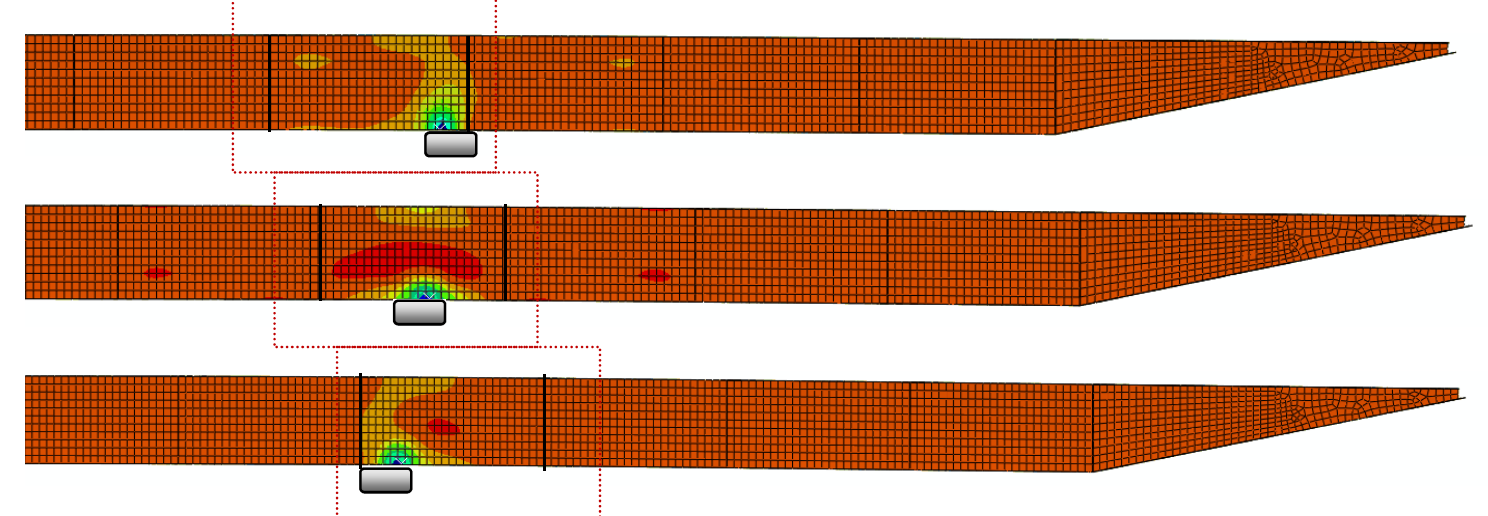

Figure 12. Evolution of vertical stresses $\mathrm{S} 22$ in panel $4 . \mathrm{t}_{\mathrm{w}}=8 \mathrm{~mm}, \mathrm{~s}_{\mathrm{s}}=50 \mathrm{~mm}$
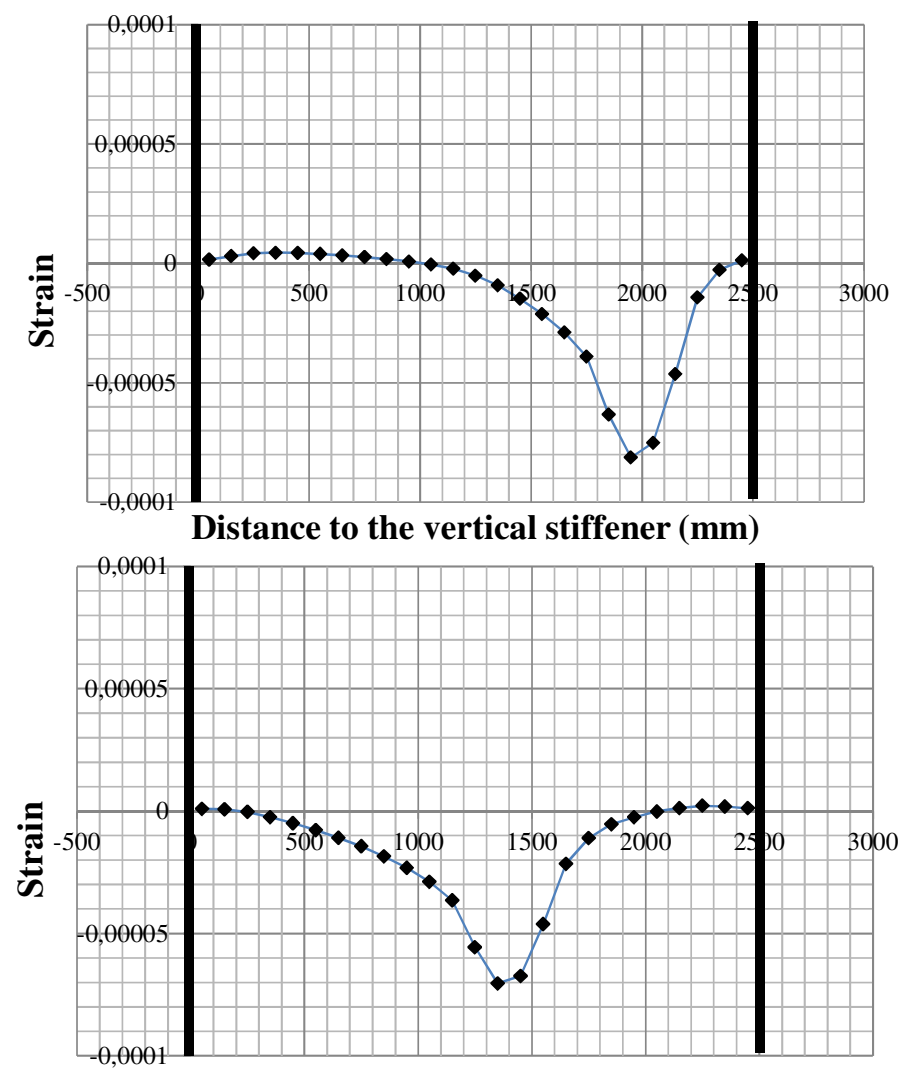

Distance to the vertical stiffener (mm)

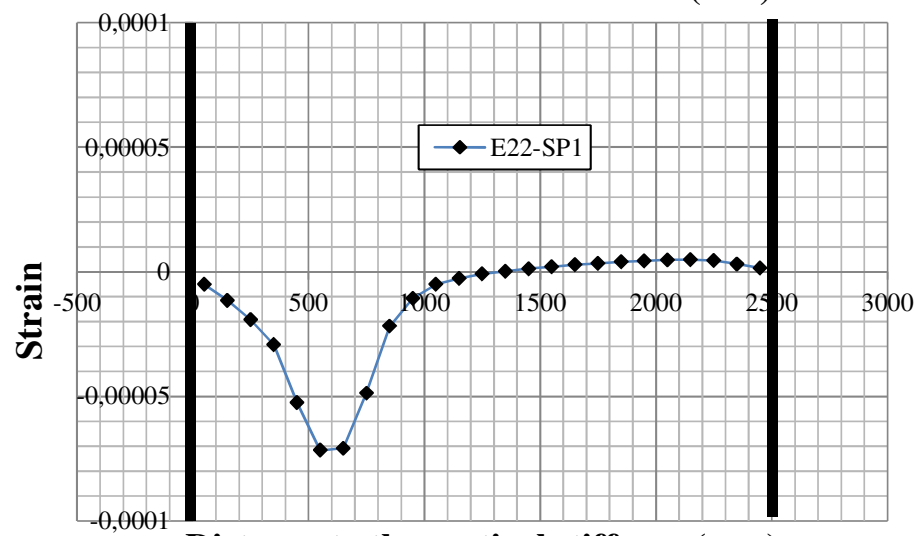

Distance to the vertical stiffener ( $\mathrm{mm})$

Figure 13. Evolution of vertical strains in panel $4 . \mathrm{t}_{\mathrm{w}}=8 \mathrm{~mm}, \mathrm{~s}_{\mathrm{s}}=50 \mathrm{~mm}$ 
1

2

3

4

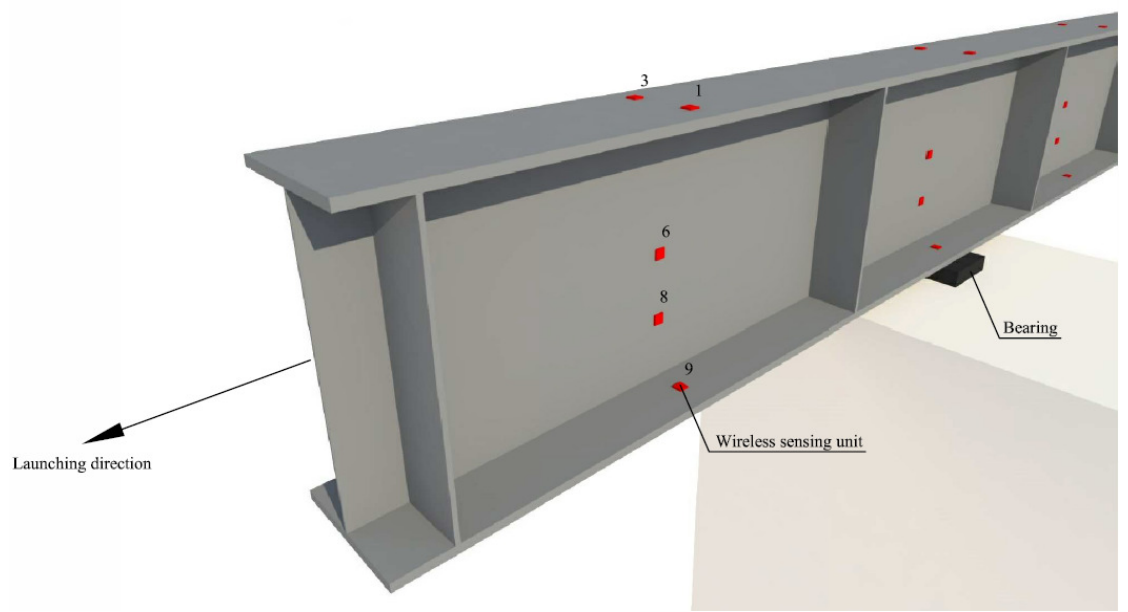

Figure 14. Isometric view of the proposed SHM deployment at panel 11.

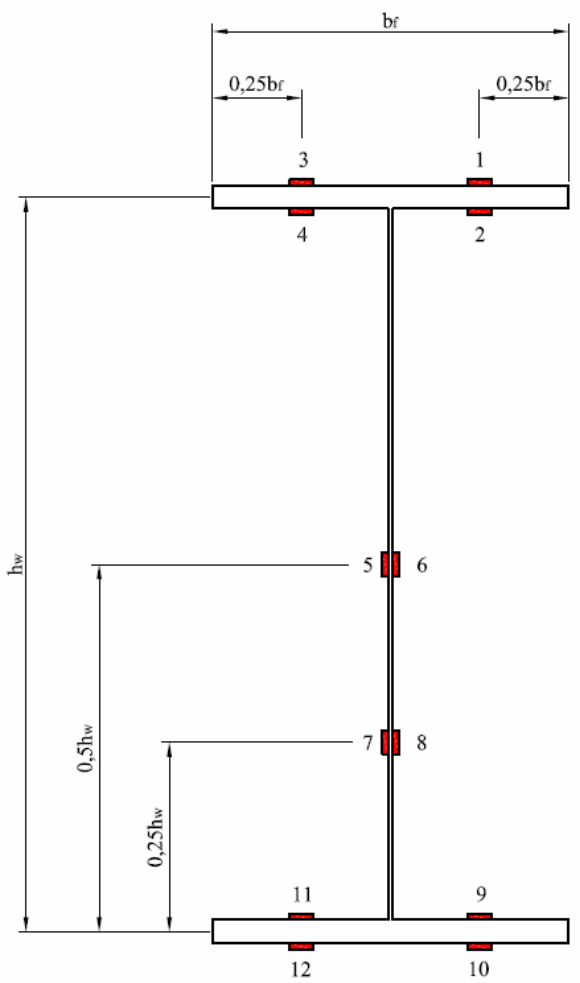

Figure 15. Cross-section of the proposed SHM deployment at panel 11. 


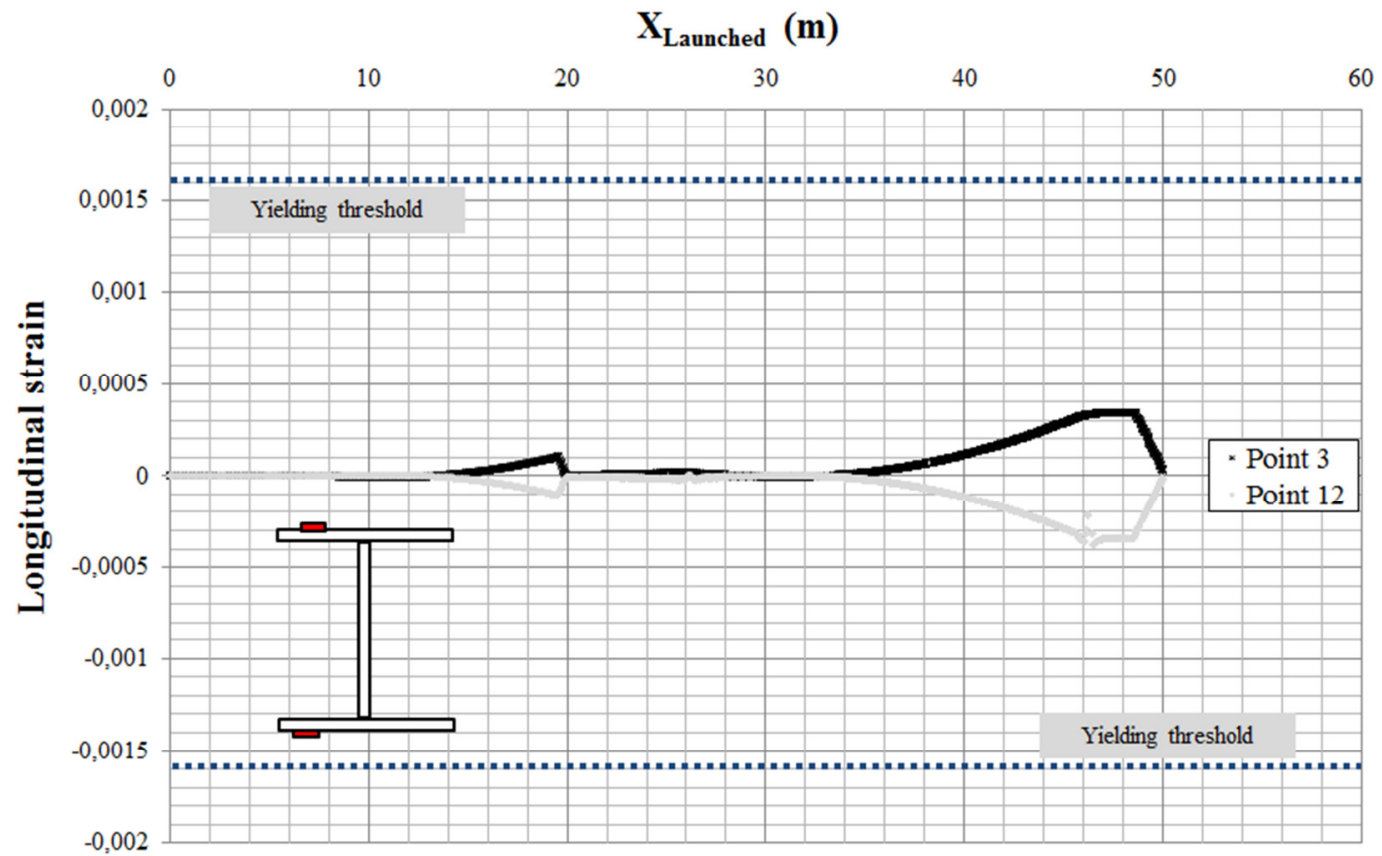

Figure 16. Evolution of the longitudinal strains measured at the pair of points 3-12.

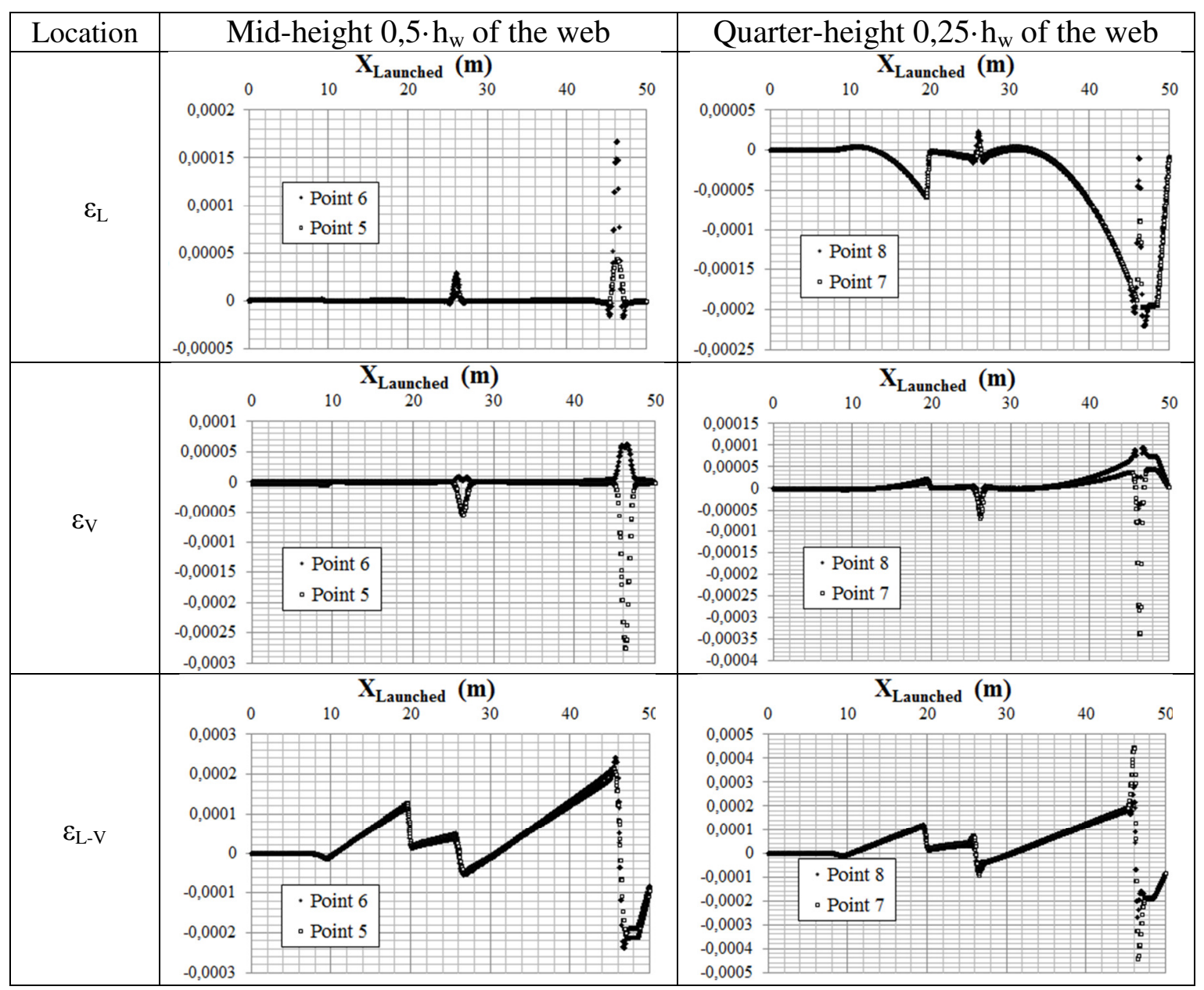

Figure 17. Evolution of strains measured at points located on the web. 


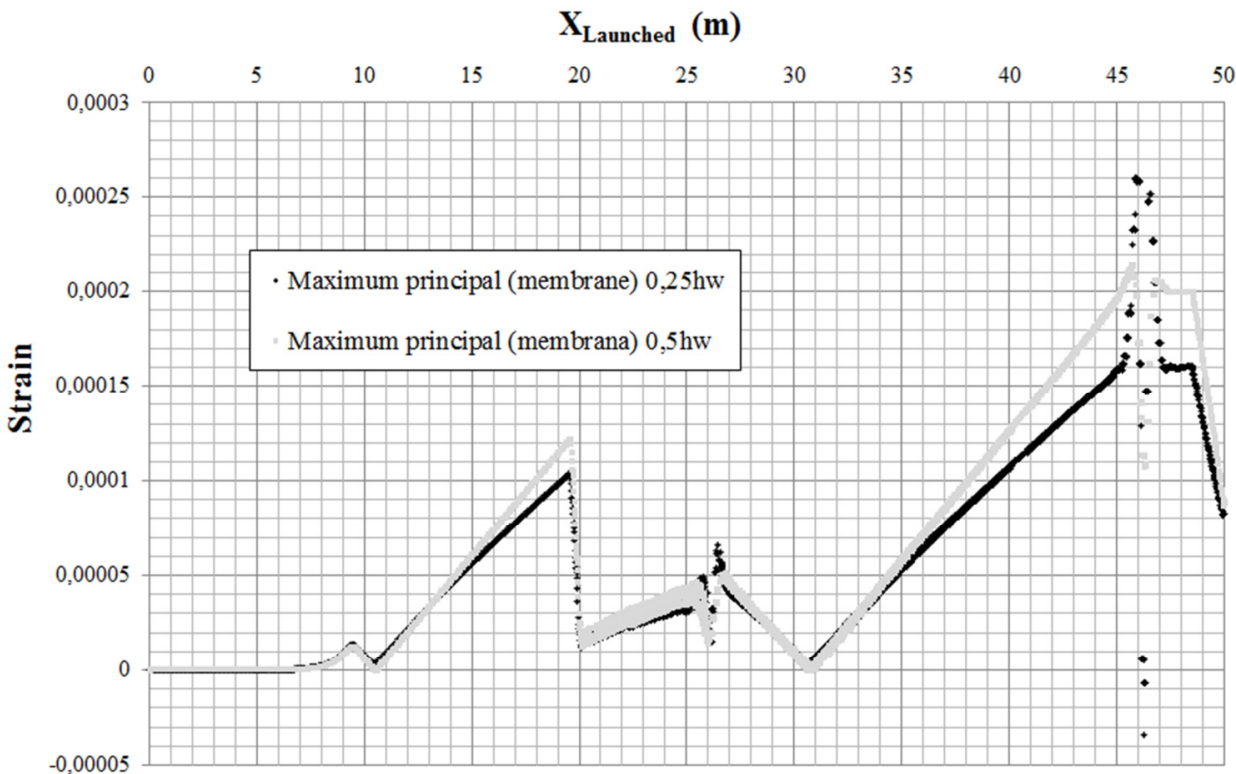

Figure 18. Evolution of the maximum principal strains measured at the web monitored points.

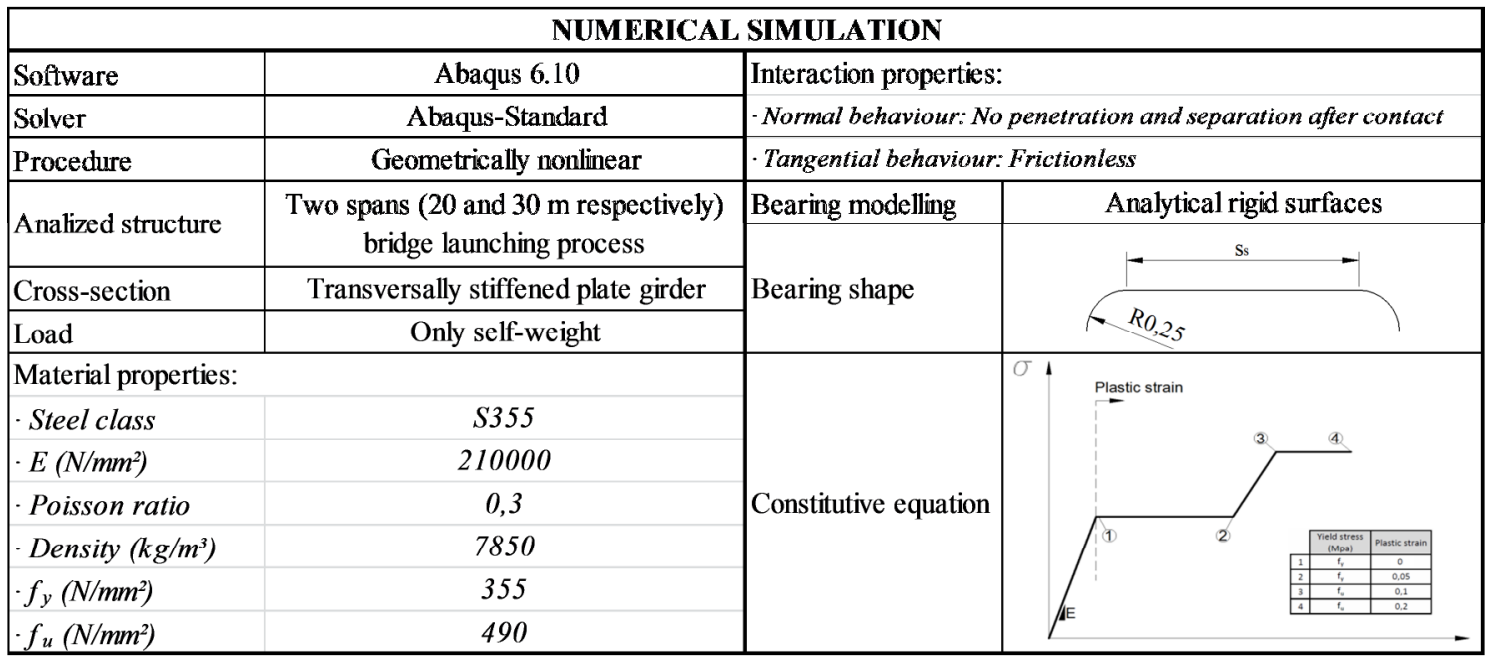




\begin{tabular}{|c|c|c|c|c|c|}
\hline Model & $\mathbf{t}_{\mathbf{w}}(\mathbf{m m})$ & $\mathbf{s}_{\mathbf{s}}(\mathbf{m m})$ & $\mathbf{e}_{\mathbf{0}}(\mathbf{m m})$ & $\mathbf{C P U}$ Time (h) & Final $\mathbf{X}_{\text {Launched }}(\mathbf{m})$ \\
\hline 1 & 4 & 50 & 4 & 39,97 & 47,95 \\
\hline 2 & 4 & 625 & 4 & 17,89 & 47,1 \\
\hline 3 & 4 & 1875 & 4 & 21,50 & 50 \\
\hline 4 & 4 & 2500 & 4 & 20,86 & 50 \\
\hline 5 & 6 & 50 & 6 & 34,61 & 50 \\
\hline 6 & 6 & 625 & 6 & 14,84 & 50 \\
\hline 7 & 6 & 1875 & 6 & 16,52 & 50 \\
\hline 8 & 6 & 2500 & 6 & 16,44 & 50 \\
\hline 9 & 8 & 50 & 8 & 40,67 & 50 \\
\hline 10 & 8 & 625 & 8 & 12,25 & 50 \\
\hline 11 & 8 & 1875 & 8 & 17,53 & 50 \\
\hline 12 & 8 & 2500 & 8 & 13,94 & 50 \\
\hline 13 & 10 & 50 & 10 & 27,23 & 50 \\
\hline 14 & 10 & 625 & 10 & 10,96 & 50 \\
\hline 15 & 10 & 1875 & 10 & 12,39 & 50 \\
\hline 16 & 10 & 2500 & 10 & 12,39 & 50 \\
\hline 17 & 12 & 50 & 12 & 27,53 & 50 \\
\hline 18 & 12 & 625 & 12 & 10,90 & 50 \\
\hline 19 & 12 & 1875 & 12 & 12,29 & 50 \\
\hline 20 & 12 & 2500 & 12 & 11,94 & 50 \\
\hline
\end{tabular}

Table 2. Parametric study. Variation of $t_{w}$ and $s_{s}$. 